Original Research Article

\title{
Comparative efficacy of pregabalin and baclofen in the rodent chronic constriction injury model of neuropathic pain
}

\author{
Saurabh Kohli*, Taruna Sharma, Juhi Kalra, Dilip C. Dhasmana
}

Department of Pharmacology, Himalayan Institute of Medical Sciences, Dehradun, Uttarakhand, India

Received: 23 October 2018

Revised: 15 November 2018

Accepted: 30 November 2018

*Correspondence to:

Dr. Saurabh Kohli,

Email: drskohli@gmail.com

Copyright: (C) the author(s), publisher and licensee Medip Academy. This is an openaccess article distributed under the terms of the Creative Commons Attribution NonCommercial License, which permits unrestricted noncommercial use, distribution, and reproduction in any medium, provided the original work is properly cited.

\begin{abstract}
Background: Neuropathic pain is associated with prolonged disability and is usually not responsive to conventional analgesics like NSAIDs and opioids. Even the recommended first-line drugs are effective in less than $50 \%$ patients. Thus, drugs with different mechanisms of action are needed. Baclofen, a GABA-B agonist has shown benefit in different types of neuropathic pains and is compared against pregabalin.
\end{abstract}

Methods: The sciatic nerve was ligated in 2 groups of 6 rats each as per the chronic constriction injury model of neuropathic pain on day 0 . After 14 days the effect of single doses of pregabalin $(30 \mathrm{mg} / \mathrm{kg})$ and baclofen $(5 \mathrm{mg} / \mathrm{kg})$ intraperitoneally were assessed over a 2 hours period. Thermal and mechanical hyperalgesia were assessed as measures of neuropathic pain by the hotplate and pin-prick method respectively.

Results: Significant thermal and mechanical hyperalgesia was produced 14 days after sciatic nerve ligation in both the groups ( $p<0.05)$. Both pregabalin ( $p$ $<0.001)$ and baclofen ( $p<0.01)$ were effective in decreasing thermal hyperalgesia throughout the two hours study period, but pregabalin was more effective as compared to baclofen $(p<0.05$ ) at 30,60 and 120minutes. Both the drugs produced a significant decrease in mechanical hyperalgesia $(p<0.01)$ throughout the study period. Again, pregabalin was the more effective drug $(\mathrm{p}<0.05)$ at all time points.

Conclusions: Significant thermal and mechanical hyperalgesia was seen 14 days after sciatic nerve ligation. Both pregabalin and baclofen were effective in reversing the hyperalgesia, but pregabalin was the more effective of the two drugs at all time points.

Keywords: Baclofen, Chronic constriction injury, Neuropathic pain, Pregabalin

\section{INTRODUCTION}

Pain is one of the most common reasons for which a person seeks medical attention. ${ }^{1}$. Though nociceptive pain is usually protective, neuropathic pain can last for months to years after the injury and can be associated with prolonged disability. ${ }^{2}$ Estimates reveal that 100 million to more than 600 million people or $1.5-8 \%$ of the world's population is afflicted at some time or the other in their lives. ${ }^{3,4}$ Neuropathic pain, which has been defined as "Pain caused by a lesion or disease of the somatosensory system" has a varied aetiology which ranges from trauma to nerves, spinal cord or even the brain, to a sequelea of diseases like Herpes, HIV/AIDS, cancer and diabetes or even as an adverse effect to many drugs. ${ }^{4-6}$ All these factors contribute to the insensitivity of neuropathic pain to conventional analgesics like NSAIDs and opioids. ${ }^{7}$ Thus, non-conventional analgesics which include various antidepressants and anticonvulsants form the mainstay of treatment and are considered first line drugs.

Unfortunately, even these are not fully effective in all types of neuropathic pain states. Present pharmacological treatments are effective in less than $50 \%$ of patients and are usually associated with many adverse effects. ${ }^{8}$ Thus, an unmet need exists where newer drugs or drugs approved for other indications can be re-channelized towards treatment of this condition. 
Animal models are commonly used to study neuropathic pain. The rodent Chronic Constriction Injury (CCI) model is one of the most commonly used and reliable models of neuropathic pain and it resembles neuropathy due to injury or trauma to peripheral nerves. ${ }^{9}$ Here we compare the efficacy of pregabalin which is one of the first line drugs and baclofen, a GABA-B agonist which has shown promising results in the treatment of neuropathic pain.

\section{METHODS}

The study was approved by the Institutional Animal Ethics Committee (HIHT/PHARMA/1-1/2010/1816). Adult Sprague-Dawley albino rats of both sexes and weighing 100-300 grams were used and divided into 2 groups of 6 animals each. Group 1 (pregabalin group) was taken as the positive control against which group 2 (baclofen group) was compared. A normal control group was not taken as pregabalin being one of the first line drugs in neuropathic pain, served as the positive control against which Baclofen was compared. Food and water were provided ad libitum and experiments were done at the same time on all days of the experiment. The CCI model of Bennett and Xie was used to produce neuropathic pain. Briefly, rats were anaesthetized with ketamine $(75 \mathrm{mg} / \mathrm{kg})$ and xylazine $(10 \mathrm{mg} / \mathrm{kg})$ given intraperitoneally (i.p). Sciatic nerve exposure was done at mid-thigh level by blunt dissection of the biceps femoralis and four chromic catgut sutures were tied loosely around the nerve till it was just indented. The incision was closed and after 14 days neuropathic pain was tested by assessing for thermal and mechanical hyperalgesia. ${ }^{10-12}$

Thermal hyperalgesia was assessed using the hot plate method whereby rats were kept on a hot plate kept which was maintained at a temperature of 50-52 degrees Celsius. The latency of the first reaction (licking, jumping, moving paws, little leaps etc.) was recorded and a cut-off of 60 seconds was kept to avoid injury. ${ }^{13}$

Mechanical hyperalgesia was evaluated by the pin-prick test. For this, a safety pin was used to touch the plantar surface of the hind paws of the rats with enough force to indent but not puncture the skin.

A normal hind paw withdrawal response was arbitrarily taken as 0.5 seconds. If the hyperalgesic withdrawal response lasted for at least 2 seconds, it was taken to be abnormally prolonged. A 15 second cut-off was taken to avoid injury. ${ }^{14}$ Commercial preparations of pregabalin (Torrent Pharmaceuticals, Solan, Himachal Pradesh) and baclofen (Intas Pharmaceuticals, Ahmedabad) were used. The drugs were dissolved in $0.9 \%$ normal saline and administered intraperitoneally as a single dose of $30 \mathrm{mg} / \mathrm{kg}$ (group 1) and 5mg/kg (group 2) respectively.

Readings were taken on day 0 prior to the surgical procedure; then 14 days after the surgical procedure. Readings were recorded on the $14^{\text {th }}$ day at 0 minutes (just prior to drug administration) and at 30,60 and 120 minutes after drug administration. Pregabalin was taken as the positive control.

Successful production of neuropathy was tested by comparison of day 0 readings (normal) with the 0 -minute readings on day 14 in both the groups.

The effect of each individual drug was assessed by comparing the 0 -minute values with those at 30,60 and 120 minutes respectively so that the time of onset of action and its sustainability over a period of 2 hours could be seen. The efficacy of each individual drug in reversing the neuropathy was assessed by comparing the day 0 (normal) values with those at time 30,60 and 120minutes on day 14 .

Finally, the effect of baclofen was compared with the recommended first line drug pregabalin by comparing the mean change in effect at times 30,60 and 120minutes.

\section{Statistical analysis}

Data were analyzed by using the 'student $\mathrm{t}$ test' in Microsoft Excel 2007.The paired t-test was used to evaluate the effect of both the drugs in reversing the neuropathy; the unpaired t-test was used to compare the effect of baclofen with the positive control pregabalin at different time points.

\section{RESULTS}

Sciatic nerve ligation was performed as per the chronic constriction injury model of Bennett and Xie. Thermal and mechanical hyperalgesia were taken as measures of neuropathy and were assessed by the hot plate and pinprick method respectively. After 14 days, a significant degree of neuropathy ( $\mathrm{p}<0.05)$ was produced in both the groups as assessed by comparing the values on day 0 (before sciatic nerve ligation) and day 14, at time 0 (prior to drug administration) (Table 1).

On day 14 , pregabalin $(30 \mathrm{mg} / \mathrm{kg})$ and baclofen $(5 \mathrm{mg} / \mathrm{kg})$ were administered intraperitoneally and thermal and mechanical hyperalgesia were assessed 30, 60 and 120minutes after drug administration. Both the drugs showed significant antinociceptive activity as shown by a significant effect on reversal of both thermal and mechanical hyperalgesia at all time points during the study period (Tables 2 and 3).

This was assessed by comparing the 0 -minute values to those at 30, 60 and 120 minutes so that the onset of action and its sustainability over a two hours period could be seen. The efficacy of the two drugs was also gauged by comparing the 'normal' values on day 0 to the 30,60 and 120minute values on day 14 (Tables 4 and 5). Pregabalin was able to reverse both thermal and mechanical hyperalgesia to near 'normal' readings as judged by a statistical non-significance between the day 0 'normal' readings and those at 30, 60 and 120 minutes on day 14 . 
Table 1: Effect of sciatic nerve ligation on production of neuropathic pain (as assessed by changes in thermal and mechanical hyperalgesia).

\begin{tabular}{|c|c|c|c|c|c|c|c|}
\hline \multirow[b]{3}{*}{ Group } & \multirow{3}{*}{$\begin{array}{l}\text { No. of } \\
\text { rats }\end{array}$} & \multicolumn{6}{|c|}{ Observations(seconds) (Mean \pm SE) } \\
\hline & & \multicolumn{3}{|c|}{ Thermal hyperalgesia } & \multicolumn{3}{|c|}{ Mechanical hyperalgesia } \\
\hline & & $\begin{array}{l}\text { Day } 0 \\
\text { (normal) }\end{array}$ & $\begin{array}{l}\text { Day } 14 \\
\text { 0 minutes } \\
\text { (before drug) }\end{array}$ & $P$ value & $\begin{array}{l}\text { Day } 0 \\
\text { (normal) }\end{array}$ & $\begin{array}{l}\text { Day } 14 \\
\text { 0 minutes } \\
\text { (before drug) }\end{array}$ & $P$ value \\
\hline $\begin{array}{l}\text { Pregabalin } \\
(30 \mathrm{mg} / \mathrm{kg} \text { i.p) }\end{array}$ & 6 & $39.66 \pm 1.64$ & $18 \pm 1.68$ & $\mathrm{P} \leq 0.001$ & $0.5 \pm 0$ & $5 \pm 0.85$ & $\mathrm{P} \leq 0.05$ \\
\hline $\begin{array}{l}\text { Baclofen } \\
(5 \mathrm{mg} / \mathrm{kg} \text { i.p) }\end{array}$ & 6 & $47.50 \pm 2.31$ & $26.16 \pm 3.10$ & $\mathrm{P} \leq 0.001$ & $0.5 \pm 0$ & $3.66 \pm 0.80$ & $\mathrm{P} \leq 0.05$ \\
\hline
\end{tabular}

Table 2: Effect of pregabalin and baclofen on reduction of thermal hyperalgesia.

\begin{tabular}{|llllll|}
\hline \multirow{2}{*}{$\begin{array}{l}\text { Group } \\
\text { No. of albino rats }\end{array}$} & \multicolumn{4}{ll}{ Observations (seconds) Mean \pm SE } \\
\cline { 2 - 6 } & & $\mathbf{0} \mathbf{~ m i n}$ & $\mathbf{3 0}$ min & $\mathbf{6 0}$ min & $\mathbf{1 2 0}$ min \\
\hline Pregabalin (30mg/kg i.p.) & 6 & $18 \pm 1.68$ & $37.33 \pm 2.20^{\dagger \dagger}$ & $38.5 \pm 1.99^{\dagger \dagger}$ & $36.5 \pm 1.72^{\dagger \dagger}$ \\
\hline Baclofen (5 mg/kg i.p.) & 6 & $26.16 \pm 3.10$ & $37.16 \pm 2.11^{\dagger}$ & $38.66 \pm 2.27^{\dagger \dagger}$ & $38 \pm 2.33^{\dagger}$ \\
\hline
\end{tabular}

$\dagger \mathrm{p} \leq 0.01$ vs values at 0 minutes (just before drug administration); $\uparrow \uparrow \mathrm{p} \leq 0.001$ vs values at 0 minutes (just before drug administration).

Table 3: Effect of Pregabalin and Baclofen on reduction of mechanical hyperalgesia.

\begin{tabular}{|c|c|c|c|c|c|}
\hline \multirow{3}{*}{ Group } & \multirow{3}{*}{ No. of albino rats } & \multicolumn{4}{|c|}{ Observations (seconds) Mean \pm SE } \\
\hline & & \multicolumn{4}{|c|}{ Day 14} \\
\hline & & 0 min & $30 \mathrm{~min}$ & $60 \mathrm{~min}$ & 120 min \\
\hline Pregabalin (30mg/kg i.p.) & 6 & $5 \pm 0.85$ & $0.91 \pm 0.41^{\dagger \dagger}$ & $0.91 \pm 0.41^{\dagger \dagger}$ & $1.33 \pm 0.58^{\dagger \dagger}$ \\
\hline Baclofen (5 mg/kg i.p.) & 6 & $3.66 \pm 0.80$ & $1.33 \pm 0.52^{\dagger \dagger}$ & $1 \pm 0.31^{\dagger \dagger}$ & $1.5 \pm 0.31^{\dagger}$ \\
\hline
\end{tabular}

$\dagger \mathrm{p} \leq 0.05$ vs values at 0 minutes (just before drug administration); $\dagger \dagger \mathrm{p} \leq 0.01$ vs values at 0 minutes (just before drug administration).

Table 4: Antinociceptive potential of pregabalin and baclofen in reversing thermal hyperalgesia towards 'normal' values.

\begin{tabular}{|c|c|c|c|c|c|}
\hline \multirow{3}{*}{ Group } & \multirow{3}{*}{$\begin{array}{l}\text { No. of } \\
\text { albino rats }\end{array}$} & \multicolumn{4}{|c|}{ Observations (seconds) Mean \pm SE } \\
\hline & & Day 0 & Day 14 & & \\
\hline & & 'Normal' values & $30 \mathrm{~min}$ & $60 \mathrm{~min}$ & $120 \mathrm{~min}$ \\
\hline Pregabalin (30 mg/kg i.p.) & 6 & $39.66 \pm 1.64$ & $37.33 \pm 2.20^{\dagger}$ & $38.5 \pm 1.99^{\dagger}$ & $36.5 \pm 1.72$ \\
\hline Baclofen (5 mg/kg i.p.) & 6 & $47.50 \pm 2.31$ & $37.16 \pm 2.11^{*}$ & $38.66 \pm 2.27 *$ & $38 \pm 2.33^{*}$ \\
\hline
\end{tabular}

$* \mathrm{p} \leq 0.001$ vs normal values on day $0 ; \uparrow \mathrm{p}>0.05$ vs normal values on day 0 .

Table 5: Antinociceptive potential of Pregabalin and Baclofen in reversing mechanical hyperalgesia towards 'normal' or preneuropathy values.

\begin{tabular}{|c|c|c|c|c|c|}
\hline \multirow{3}{*}{ Group } & \multirow{3}{*}{$\begin{array}{l}\text { No. of } \\
\text { albino rats }\end{array}$} & \multicolumn{4}{|c|}{ Observations (seconds) Mean \pm SE } \\
\hline & & Day 0 & Day 14 & & \\
\hline & & 'Normal' values & $30 \mathrm{~min}$ & $60 \mathrm{~min}$ & $120 \mathrm{~min}$ \\
\hline Pregabalin (30 mg/kg i.p.) & 6 & $0.5 \pm 0$ & $0.91 \pm 0.41^{\dagger}$ & $0.91 \pm 0.41^{\dagger}$ & $1.33 \pm 0.58^{\dagger}$ \\
\hline Baclofen (5 mg/kg i.p.) & 6 & $0.5 \pm 0$ & $1.33 \pm 0.52^{\dagger}$ & $1 \pm 0.31^{\dagger}$ & $1.5 \pm 0.31^{*}$ \\
\hline
\end{tabular}

$* \mathrm{p} \leq 0.05$ vs normal values on day $0 ; \uparrow \mathrm{p}>0.05$ vs normal values on day 0 .

Baclofen was not able to reverse thermal hyperalgesia to 'normal' values $(\mathrm{p}<0.001)$ but was able to reverse mechanical hyperalgesia to near normal values $(\mathrm{p}>0.05)$ at 30 and 60 minutes but the effect decreased by 120 minutes $(\mathrm{p}<0.05)$. The effect of baclofen was compared to the positive control pregabalin by comparing the mean change) in reaction times (from 0-minute values at 30, 60 and 120 minutes between the two groups. In comparison to pregabalin, baclofen was less efficacious in reversing both 
thermal and mechanical hyperalgesia ( $p<0.05$ for both) (Table 6).

\section{DISCUSSION}

In this study, we assessed the efficacy of the gabapentinoid pregabalin and the GABA-B agonist baclofen in the CCI model of neuropathic pain. Studies of pregabalin in animal models of NP have shown it to be effective in reducing both thermal and mechanical hyperalgesia. In a study in which neuropathy was produced by partial sciatic nerve ligation in rats, pregabalin, given in a dose of $10-30 \mathrm{mg} / \mathrm{kg}$ i.v dose dependently reversed both thermal and mechanical hyperalgesia. Pregabalin completely reversed the thermal hyperalgesia, but it's effects on mechanical hyperalgesia were partial, producing around $70 \%$ reversal as compared to pre-neuropathy levels. ${ }^{15}$

Table 6: Comparative antinociceptive effects of positive control Pregabalin with Baclofen on thermal and mechanical hyperalgesia(Expressed as mean change in reaction times(from 0 minute values) \pm SE.

\begin{tabular}{|c|c|c|c|c|c|c|c|}
\hline \multirow{4}{*}{ Group } & \multirow{4}{*}{$\begin{array}{l}\text { No. of } \\
\text { albino } \\
\text { rats }\end{array}$} & \multicolumn{6}{|c|}{ Observations(seconds) (Mean change in reaction times $\pm \mathrm{SE}$} \\
\hline & & \multicolumn{3}{|c|}{ Thermal hyperalgesia } & \multicolumn{3}{|c|}{ Mechanical hyperalgesia } \\
\hline & & Day 14 & & & Day 14 & & \\
\hline & & $30 \mathrm{~min}$ & $60 \mathrm{~min}$ & $90 \mathrm{~min}$ & $30 \mathrm{~min}$ & $60 \mathrm{~min}$ & $90 \mathrm{~min}$ \\
\hline $\begin{array}{l}\text { Pregabalin } \\
(30 \mathrm{mg} / \mathrm{kg} \text { i.p) }\end{array}$ & 6 & $19.33 \pm 2.76$ & $20.5 \pm 2.81$ & $18.5 \pm 2.22$ & $4.08 \pm 0.63$ & $4.08 \pm 0.63$ & $4.16 \pm 0.87$ \\
\hline $\begin{array}{l}\text { Baclofen } \\
(5 \mathrm{mg} / \mathrm{kg} \text { i.p) }\end{array}$ & 6 & $11 \pm 2.07^{\dagger}$ & $12.5 \pm 1.51^{\dagger}$ & $11.83 \pm 1.73^{\dagger}$ & $2.33 \pm 0.38^{\dagger}$ & $2.33 \pm 0.27^{\dagger}$ & $2 \pm 0.49^{\dagger}$ \\
\hline
\end{tabular}

$\uparrow \mathrm{p} \leq 0.05$ vs pregabalin.

Other studies utilizing the streptozocin induced diabetic neuropathy model have also showed a significant dose dependant reduction, but not complete reversal of both thermal and mechanical hyperalgesia by pregabalin in doses of $3-30 \mathrm{mg} / \mathrm{kg}$ p.o. ${ }^{16}$ Different route as well as the different model used in this study may have caused the discrepancy in results for mechanical hyperalgesia as compared to our study. In another study, pregabalin was found to reduce secondary mechanical hyperalgesia induced by mild thermal injury(which corresponds to mechanical hyperalgesia of neuropathic pain) at doses of $30 \mathrm{mg} / \mathrm{kg}$ i.p. Doses of $100 \mathrm{mg} / \mathrm{kg}$ i.p. were effective in completely reversing the mechanical hyperalgesia. ${ }^{17}$ Studies of gabapentin which has a similar mechanism of action as pregabalin, given by different routes in the CCI model have shown a dose dependant reversal of thermal hyperalgesia but only a partial reversal of mechanical allodynia and hyperalgesia. ${ }^{18}$

Human clinical trials have supported the efficacy seen in animal models, with a large number of trials showing a significant benefit for pregabalin in different neuropathic pain states. ${ }^{19}$ Pregabalin, which acts via the $\alpha 2 \delta$ subunit of the $\mathrm{N}$ type calcium channels, is recommended in diabetic peripheral neuropathy, post herpetic neuropathic pain and in neuropathic pain associated with spinal cord injury by the FDA. ${ }^{20}$

Baclofen has also shown efficacy in different neuropathic pain states both in animal models and in clinical trials. ${ }^{21,22}$ In present study, baclofen in a dose of $5 \mathrm{mg} / \mathrm{kg}$ i.p. produced a significant, but not complete reversal of thermal and mechanical hyperalgesia. In models utilizing the CCI model in rats, baclofen, in a dose range of $1-30 \mathrm{mg} / \mathrm{kg}$ subcutaneously produced a dose dependent reversal of thermal hyperalgesia. The dose of $15 \mathrm{mg} / \mathrm{kg}$ produced a significant, but not complete reversal $(\approx 80 \%$ reversal) of thermal hyperalgesia. Doses above this, though producing complete reversal, were associated significant motor deficits and sedation. The effects on mechanical hyperalgesia were not evaluated in this study. ${ }^{21}$ In another study, baclofen in doses of $1-8 \mathrm{mg} / \mathrm{kg}$ p.o. produced a dose dependent decrease, but not complete reversal of scratching behavior and thermal hyperalgesia in a CCI model in rats. ${ }^{23}$ Both these studies are in agreement with our results, whereby baclofen $5 \mathrm{mg} / \mathrm{kg}$ could produce only partial reversal of mechanical and thermal hyperalgesia. Randomized controlled trials in humans have shown it to be effective in post herpetic neuralgia, diabetic peripheral neuropathy and trigeminal neuralgia. ${ }^{24}$

\section{CONCLUSION}

In conclusion, authors showed that both pregabalin and baclofen were effective in reversing neuropathic pain in the CCI model. Pregabalin was clearly more effective than baclofen in reversing both thermal and mechanical hyperalgesia at the doses used in our study.

\section{ACKNOWLEDGEMENTS}

Authors would like to thank the support of the management SRH University and the faculty and staff of Department of Pharmacology, SRHU, Dehradun, India. 
Funding: No funding sources

Conflict of interest: None declared

Ethical approval: The study was approved by the Institutional Ethics Committee (HIHT/PHARMA/1$1 / 2010 / 1816)$

\section{REFERENCES}

1. Salter MW. Deepening understanding of the neural substrates of chronic pain. Brain. $2014 \mathrm{Feb}$ 17;137(3):651-3.

2. Costigan M, Scholz J, Woolf CJ. Neuropathic pain: a maladaptive response of the nervous system to damage. Annual Rev Neurosci. 2009 Jul 21;32:1-32.

3. Bouhassira D, Attal N. Translational neuropathic pain research: a clinical perspective. Neurosci. 2016 Dec 3;338:27-35.

4. Alles SR, Smith PA. Etiology and pharmacology of neuropathic pain. Pharmacol Rev. 2018 Apr 1;70(2):315-47.

5. Jensen TS, Baron R, Haanpää M, Kalso E, Loeser JD, Rice AS, et al. A new definition of neuropathic pain. Pain. 2011 Oct;152(10):2204-5.

6. Schmidt BL, Hamamoto DT, Simone DA, Wilcox GL. Mechanism of cancer pain. Molecular Intervent. 2010 Jun;10(3):164.

7. Yekkirala AS, Roberson DP, Bean BP, Woolf CJ. Breaking barriers to novel analgesic drug development. Nature Rev Drug Discovery. 2017 Aug;16(8):545.

8. Finnerup NB, Attal N, Haroutounian S, McNicol E, Baron R, Dworkin RH, et al. Pharmacotherapy for neuropathic pain in adults: a systematic review and meta-analysis. Lancet Neurol. 2015 Feb 1;14(2):16273.

9. Colleoni M, Sacerdote P. Murine models of human neuropathic pain. Biochimica et Biophysica Acta (BBA)-Molecular Basis Dis. 2010 Oct 1;1802(10):924-33.

10. Bennett GJ, Xie YK. A peripheral mononeuropathy in rat that produces disorders of pain sensation like those seen in man. Pain. 1988 Apr 1;33(1):87-107.

11. Wanj LX, Wanj ZJ. Animal and cellular models of chronic pain. Adv Drug Delivery Rev. 2003; 5:949-65.

12. Vogel GH, Vogel WGH, editors, Drug discovery and evaluation- pharmacological assays. 2nd ed. New York: Verlog Springer publication; 1996.

13. Wang YX, Bowersox SS, Pettus M, Gao DA. Antinociceptive properties of fenfluramine, a serotonin reuptake inhibitor, in a rat model of neuropathy. J Pharmacol Experimental Therapeut. 1999 Dec 1;291(3):1008-16.

14. Gonzalez MI, Field MJ, Hughes J, Singh L. Evaluation of selective NK1 receptor antagonist CI-1021 in animal models of inflammatory and neuropathic pain. J Pharmacol Experiment Therapeut. 2000 Aug 1;294(2):444-50.

15. Chen SR, Xu Z, Pan HL. Stereospecific effect of pregabalin on ectopic afferent discharges and neuropathic pain induced by sciatic nerve ligation in rats. Anesthesiology: J Am Soc Anesthesiologists. 2001 Dec 1;95(6):1473-9.

16. Field MJ, McCleary S, Hughes J, Singh L. Gabapentin and pregabalin, but not morphine and amitriptyline, block both static and dynamic components of mechanical allodynia induced by streptozocin in the rat. Pain. 1999 Mar 1;80(1-2):391-8.

17. Jones DL, Sorkin LS. Systemic gabapentin and S (+)3-isobutyl- $\gamma$-aminobutyric acid block secondary hyperalgesia. Brain Res. 1998 Nov 9;810(1-2):93-9.

18. Gilron I, Flatters SJ. Gabapentin and pregabalin for the treatment of neuropathic pain: A review of laboratory and clinical evidence. Pain Res Management. 2006;11(Suppl A):16A-29A.

19. Dworkin RH, O'Connor AB, Audette J, Baron R, Gourlay GK, Haanpaa ML, et al. Recommendations for the pharmacological management of neuropathic pain: an overview and literature update. InMayo Clin Proc. 2010;85(3):S3-S14.

20. FDA. Highlights of prescribing information Lyrica (Pregabalin). Available at: https://www.accessdata.fda.gov/drugsatfda_docs/labe 1/2012/021446s028lbl.pdf. Accessed 09 October 2018.

21. Franek M, Vaculin S, Rokyta R. GABA B receptor agonist baclofen has non-specific antinociceptive effect in the model of peripheral neuropathy in rat. Physiological Res. 2004 Jan 1;53:351-5.

22. Smith TE, Chong MS. Neuropathic pain. Hospital Med. 2000;6:760-6.

23. Santos TJF, Castro-Costa CM, Giffoni SDA, Santos FJC, Ramos RSN, Gifoni MAC. The effect of baclofen on spontaneous and evoked behavioural expression of experimental neuropathic chronic pain. Arq Neuropsiquiatr. 1999;57(3):753-760.

24. Attal N, Cruccu G, Haanpää M, Hansson P, Jensen TS, Nurmikko $\mathrm{T}$, et al. EFNS guidelines on pharmacological treatment of neuropathic pain. Eur $\mathbf{J}$ Neurol. 2006 Nov;13(11):1153-69.

Cite this article as: Kohli S, Sharma T, Kalra J, Dhasmana SC. Comparative efficacy of pregabalin and baclofen in the rodent chronic constriction injury model of neuropathic pain. Int J Basic Clin Pharmacol 2019;8:133-7. 